\title{
Improving Primo Usability and Teachability with Help from the Users
}

\author{
Barbara Valentine \\ Linfield College \\ Beth West \\ Linfield College
}

Follow this and additional works at: https://digitalcommons.linfield.edu/librariesfac_pubs

Part of the Curriculum and Instruction Commons, Graphics and Human Computer Interfaces Commons, and the Information Literacy Commons

\section{DigitalCommons@Linfield Citation}

Valentine, Barbara and West, Beth, "Improving Primo Usability and Teachability with Help from the Users" (2016). Faculty \& Staff Publications. Accepted Version. Submission 14.

https://digitalcommons.linfield.edu/librariesfac_pubs/14

This Accepted Version is protected by copyright and/or related rights. It is brought to you for free via open access, courtesy of DigitalCommons@Linfield, with permission from the rights-holder(s). Your use of this Accepted Version must comply with the Terms of Use for material posted in DigitalCommons@Linfield, or with other stated terms (such as a Creative Commons license) indicated in the record and/or on the work itself. For more information, or if you have questions about permitted uses, please contact digitalcommons@linfield.edu. 
Improving Primo Usability and Teachability with Help from the Users

Barbara Valentine, Professor, Teaching and Systems Librarian

Nicholson Library

Linfield College

900 SE Baker Street

McMinnville OR 97128

bvalen@linfield.edu; 503-883-2573

Beth West, Assistant Professor, Teaching and Online Learning Librarian

Nicholson Library

Linfield College

900 SE Baker Street

McMinnville OR 97128

bwest@linfield.edu; 503-883-2595

Acknowledgements:

Special thanks to our readers: Kathleen Spring, Collections Management Librarian and Susan Barnes Whyte, Linfield College Library Director 


\begin{abstract}
:
In the aftermath of a consortium migration to a shared cloud-based resource management and discovery system, a small college library implemented a web usability test to uncover the kinds of difficulties students had with the new interface. Lessons learned from this study led to targeted changes, which simplified aspects of searching, but also enhanced the librarians' ability to teach more effectively. The authors discuss the testing methods, results, and teaching opportunities, both realized and potential, which arose from implementing changes.

Keywords: Web-scale discovery; Primo; Web usability testing; User experience; Information Literacy; Instruction
\end{abstract}




\section{Introduction}

Migration to any new system is challenging; migrating to a cloud-based shared resource management and discovery system with 36 other libraries is beyond overwhelming. Implementing such a system involves myriad decisions often made on the fly, based partly on experience with the previous systems and partly on discussions with staff and other consortium institutional members. All of this progress creates upheaval in the migrating library, including overhauled staff workflows, increased troubleshooting challenges, and even changes in the language used to communicate among affected staff and with library users.

While librarians try to minimize, even shield, end-users from as much disruption as possible, students and faculty still wind up interacting with a new product, one that demands they familiarize themselves with new design, navigation, wording choices, symbols and even expanded access to different resources, such as full text articles, e-books, and other e-content. Teaching librarians, whether deeply involved in the migration or not, must shift gears to acquaint both themselves and their publics with the new state of affairs. Not only are these cloud-based systems new and evolving, their potential as a next-generation searching tool has yet to be fully realized, much less well understood by those instructing others in its best use.

As Web-scale discovery systems evolve, and libraries continue to acquire them, librarians must find creative ways to teach them effectively. The primary purpose of this article is to build on the research in this area by presenting strategies for teaching inspired by usability testing results. The article also adds to the literature by documenting usability testing of a discovery system by a small library within a consortium environment. Using a quick Web usability study, the authors uncovered issues and common misconceptions about using our new Primo (Ex Libris) discovery system, which led to improvements that also facilitated instruction. We briefly 
discuss testing methods and highlight some valuable modifications. In addition, we describe unexpected teaching opportunities, both realized and potential, which arose from implementing some of these simple changes.

\section{User Experience Testing After a Major Consortium Migration}

In January 2015, the Orbis Cascade Alliance (Alliance) became the first library consortium to migrate to the Ex Libris combined Alma/Primo cloud-based resource management and discovery system. The enterprise took 37 libraries two years in four cohort stages (Orbis Cascade Alliance 2015). Linfield College, a small private four-year college, belonged to the first cohort, and therefore was among the first in the consortium to migrate.

While the Alliance offered a template for configuring a common out-of the-box Primo, a public face for the combined system, every institution in the consortium also adjusted the interface to fit perceived local patron needs and available systems expertise. The Alliance's Primo allowed a high degree of customization, including drop-down scopes and/or tabs either to focus or combine content, side facets to limit results, and access to a back end to change labels, CSS, and other viewing options. In addition, the interface included access to a Primo Central Index (PCI), "a mega-aggregation of hundreds of millions of scholarly e-resources of global and regional importance" (Ex Libris 2016), providing institutions the ability to integrate articles and other e-content into results alongside a library’s physical holdings. About half the Alliance institutions had never experienced a discovery system that combined books and articles in search results. This fact, combined with the need to make choices quickly about an interface with which

few were familiar to accommodate a relentless migration schedule likely contributed to differing institutional approaches to configuring Primo at the outset. 
Linfield College librarians viewed Primo migration as essentially a replacement of the WorldCat Local (WCL) discovery interface, which had allowed for minimal customization. The library staff stuck closely to the out-of-the-box Primo installation in order to simplify the process but also from a desire to see how the vendor-intended system would operate for patrons before making major alterations. The hope was that by swapping out the WCL embedded search box on the main library page with a similar-looking Primo search box, local users would experience the least possible disruption to their searching routines. After migration, understanding how patrons were experiencing Primo became a top priority for guiding ongoing development decisionmaking and future enhancements.

When the first cohort went live with Primo in June 2013, various Linfield Library staff members made a first attempt to gauge public opinion by gathering anecdotal and observational evidence informally at the reference desk and during instruction sessions. At the end of fall semester 2013, one of the researchers conducted a more structured inquiry, interviewing 12 course instructors in half-hour sessions through which participants voiced general reactions to the new interface and also demonstrated a typical search. These investigations highlighted issues that assisted librarians with making informed changes to some labeling and to adjust mechanisms that were adversely affecting search results. In addition, the feedback exposed larger problems, not previously obvious to staff, that required further investigation and interaction with the vendor.

The discovery interface continued to evolve as new institutions migrated and vendor development progressed. Despite all this volatility, Linfield patrons generally approved of the new discovery system. When asked, most people said that, anomalies aside, they had not found the transition to be onerous and generally had found what they were seeking. These testimonials 
surprised library staff, especially those people grappling with the huge backend changes of the new combined discovery and resource management systems. Perhaps for students and faculty already familiar with WCL discovery searching, the initial transition to Primo was not that dramatic. In addition, librarians did not really change their teaching approaches, and so continued to help patrons in a similar manner as before migration. But the question of how best to teach Primo, especially in this novel consortial environment, continued to arise.

\section{Web-scale discovery and teaching}

In earlier literature, Vaughn (2011) provides a fine overview of Web-scale discovery in the library environment and describes the first services on the market, led by OCLC in 2007. Richardson (2013) surveys the growth of Web-scale discovery tools and their impact on search and the library profession. Way (2010) describes the impact of Summon (Serial Solutions) on the use of library resources at Grand Valley State University, while Buck and Melinger (2011) explore Summon's effect on information literacy instruction at Oregon State University. More recent articles describing and evaluating Web-scale discovery services include Breeding's comments about the state of the technology (2014a) and its challenges (2014b). While still relatively new and evolving, the use of these systems in academic libraries continues to grow. Kevin Seeber (2015) provides an excellent literature review on Web-scale discovery systems in academic libraries. Joseph Deodato (2015) offers a current and comprehensive blueprint from the Rutgers experience of selecting such a system. The literature on the usability of the Primo Webscale discovery system specifically has grown recently, especially its use at larger institutions. Comeaux (2012) conducted usability testing on Primo at Tulane University and found that patrons rated it favorably, especially after making a few local terminology changes. Testing by 
Perrin et al. (2014) at Texas Tech University similarly found that small changes made a big difference, concluding "[T]he majority of patrons might be happier with a tool with less capability and simpler options rather than a complex tool with many different ways to approach their search." Nichols et al. (2014) also suggested that despite mixed attitudes toward Primo during testing, users eventually adapted to initial "bewilderment" and could search more effectively. Librarians at the University of Minnesota set up an elaborate lab to encourage ongoing web usability research (Carter et al. 2015). The University of Kansas study compares observed usability testing of Primo with measures gathered from event tracking and log analysis (Hanrath and Kottman 2015).

While Web-scale research may be ramping up, Seeber (2015) suggests there remains a paucity of research related to teaching Web-scale discovery. He notes that most studies "primarily evaluate the discovery tools themselves, with an aim of helping libraries select a service and customize its implementation, rather than assessing user behavior to guide instruction efforts" $(2015,21)$. When Seeber looked for studies on Web-scale discovery instruction, he noticed that librarians using the systems reacted fairly negatively toward them, with few actually engaged in teaching them. Similarly, Nichols et al (2014) suggested the need for more research on best practices for teaching Primo.

On a more optimistic note, Seeber also found a handful of studies that suggest discovery services offer instructors new opportunities for teaching concepts of critical thinking and evaluation, with a move away from focusing on databases. Similarly, Gross and Sheridan (2010), who researched Summon (Serials Solutions) several years ago, concluded that students got lost in the results from enormous retrievals: “...the students were not able to fully understand the results they obtained, or where those results were coming from" $(2010,244)$. They suggested 
discovery systems warranted a new approach to teaching, including an emphasis on information evaluation. Jolinda Thompson's "Practical Guide" also recognizes the challenges that discovery systems present to students, who can find lots of content but do not understand the nature of what they have retrieved. She suggests the need to help students discern differences in format, provenance, and evaluating content $(2014,104)$. Rose-Wiles and Hofmann (2013) concluded from their study that discovery systems could even facilitate the ability of librarians to promote information literacy better within the institution and vowed to develop some best practices.

The centerpiece of Seeber's article offers a new approach to teaching students the skills needed to conduct research via discovery systems more effectively. He first discusses progress on the work by Association of College and Research Libraries (ACRL) to revise the 2000 Information Literacy Competency Standards to better meet the realities of a continually evolving digital landscape. Using drafts and discussions on what has now become known as the ACRL Framework (ACRL 2015), Seeber employs a threshold concept, "format as a process," to describe ways instructors can better strengthen student discernment about the nature and content of the results they are retrieving $(2015,23-25)$.

The ACRL Framework does seem to offer a flexible approach to conceptualizing information literacy that better supports teaching in the current and changing research environment.

"Information literacy is the set of integrated abilities encompassing the reflective discovery of information, the understanding of how information is produced and valued, and the use of information in creating new knowledge and participating ethically in communities of learning" (ACRL 2015, Introduction). 
Here the Framework encourages instructors to focus more on the content and value of information discovered than on the structures used to find it.

Seeber's suggestions of ways to incorporate the Framework into information literacy lessons seemed to converge handily with the Linfield librarians' desire to understand better how to teach with Primo more effectively. But first, the teaching librarians wanted to know how student research needs were already being met, or conversely were failing to be met.

\section{Web Usability Testing}

By January 2015, all the consortium libraries had migrated and the centerpiece for resource sharing among them, Summit, had been implemented. At this point, Linfield librarians experienced a more settled Primo interface for spring semester reference and teaching activities. Although we continued informal check-ins and observations with end-users about system usability, in the classroom and during reference consultations, we wanted a more structured way to see how students were responding to using the completed system at the local institution. We also understood that monthly Primo updates, along with a complete Primo facelift due in late 2016, meant that teaching with an evolving Primo would remain the status quo and wanted a method that would provide insights without requiring too much time and effort.

The researchers chose task-based Web usability testing because in the past this method had proved to be a quick and effective means of gathering contextualized input for improving and revising the library web pages. This Web usability testing method allows researchers to observe how people perform particular tasks within the context of the search, offering some truths not available through user experience assessment methods that depend primarily on computer logs or patron reports of use. Now referred to by some as one of several classic 
usability strategies (Dominguez 2015), this variety of Web usability testing also gauges how people actually navigate a Web page.

Nielsen (2001) agrees with the value of this method over user reporting: "Watch what people actually do. Do not believe what people say they do. Definitely don't believe what people predict they may do in the future." He pioneered usability testing implementation in the business world (Nielsen 2000a), deriving much of his method from established customer satisfaction testing measures (Rubin 1994). Librarians have tested library web sites using these methods for almost as long (Chisman et al. 1999; McGillis and Toms 2001; Valentine and Nolan 2002) and continue to use them today to test Primo and other cloud-based discovery systems (Carter et al. 2015).

While Web usability testing can be quite elaborate, expensive, and time-intensive, a bare bones approach is still effective for unearthing unexpected patron assumptions and Web navigation patterns. We designed and implemented a simple usability study intended to reap quick results that could inform questions we had about existing Primo configurations.

\section{Methods}

The researchers first gained Institutional Research Board (IRB) approval from the college to conduct the study, which assured test conditions and results would be safe and anonymous for student participants. We created a plan for testing, including a list of relevant participant tasks, scripts for introducing the testing, time to debrief students afterward, and layout of the "lab" used for the testing. 


\section{Participants}

The summer hiatus of 2015 proved to be the optimal time for us to implement testing; however, recruiting a variety of students from across campus during that time proved difficult. As a result, we recruited from our summer library worker pool. Two concerns arose from using this population. First, many people assume library student workers know more about searching and library systems than those in the main college population, and think they would therefore ace the testing, providing weak or atypical results. In fact, one of the authors, who has extensive experience gathering qualitative data from students both employed and not employed by a library, has found that student library workers are surprisingly naïve researchers and can provide insights as valuable as those from the regular population. Second, study participants might be more self-conscious test-takers if they knew the researchers well. In order to mitigate some of these concerns, we recruited students less familiar to us from different departments in the library, including ILL (interlibrary loan), technical services, circulation, and media services. Only one student was trained in the use of Primo for regular library work, meaning that most participants had little experience with Primo, other than for their own college assignments

We then considered how many participants to recruit. Nielsen (2000b) found that as few as five participants can reveal 85 percent of the major usability problems people encounter. Thus we agreed that nine library student workers, with different job roles in the library, would be a more than sufficient number and variety to provide insights and to reveal unexpected behaviors. The four male and five female students, with equal numbers of sophomores, juniors, and seniors, represented an assortment of majors and GPAs ranging from 2.9 to 3.8. All had received some library instruction, although only four had done so recently. See Table 1. 
Table 1: Participant Statistics

\begin{tabular}{|ll|}
\hline & \\
Gender: & 4 Male; 5 Female \\
GPA: & 2.9 to 3.89; (average: 3.5) \\
Year: & Soph (3), Junior (3), Senior (3) \\
Web Search usage: & Frequent (4); Occasional (5) \\
Primary Study Site: & Dorm (6); Library (3) \\
Library Instruction: & More than a term ago (5); This term (4) \\
Majors: & Accounting, Biology, English, Finance, International Business, \\
& International Relations (2), Political Science, Sociology \\
& \\
\hline
\end{tabular}

\section{Testing Procedure}

Each student participant signed an IRB Implied Consent Form, which described the research plan, potential risks and discomforts, and assured anonymity of results. Students also filled out a demographic survey. We chose to audio-record the sessions using what is now known as a Thinking Aloud method (Nielsen 2012). This simple method had exposed valuable insights for past Web page redesigns and seemed less intimidating for participants than video recording.

The "testing lab" consisted of a stand-up computer in one researcher's office. As shown in Figure 1, the Primo interface being tested included five scopes:

1. "Everything" - a default scope covering local records, Summit (consortial records), and article citations via Primo Central Index (PCI).

2. Linfield Libraries - local physical items and e-books in the collection

3. "Articles"- PCI-only selections.

4. "WorldCat" - a standalone API for WorldCat records from OCLC pulled into the Primo interface, but which did not integrate with Primo facets and other features

5. "Ebsco" - a standalone API for Ebsco-only databases pulled into the Primo interface, but which did not integrate with Primo facets and other features 
Figure 1 - Primo During Testing

Toolbar view

Guest te e-Sheif My Aocount Sign in

Now Search Resaarch Dutabases Class Guides Eloumals AZZ Ask Ust (chat) Helo

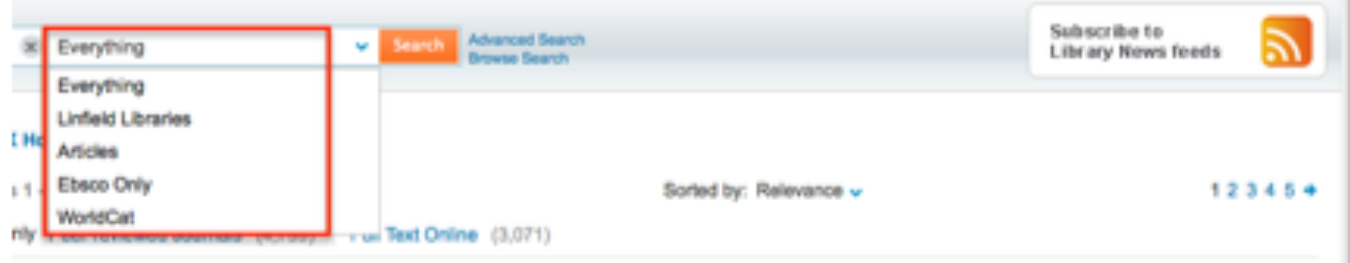

Results view: 5 scopes, labels, and Expand Results box

\& Linfield College

LIB RARIES

\section{Library Resources Course Reserves}

whales

Drss

Add page to e-Shelf

\section{Expand My Results}

\section{$\checkmark$ Expand My Results}

\section{Show only}

Peer-reviewed Journals $(7,697)$

Full Text Online $(14,273)$

Available in the Library (3)

\section{Refine My Results}

Format

Articles $(10,916)$ $\times$

Everything

Everything

Linfield Libraries

Show bX Ho

Articles

Results 1 - Ebsco Only

WorldCat

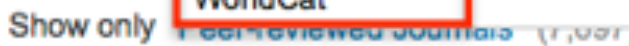

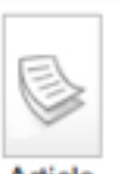

Whales

John A. Burton ; Angela King

Neture, 1074 Vel-254(5472), p.1

Article

No full-text online

Get It Details Reviews \& T

The time the whale came to Ja Jeanne Evernden Bruce Miller; $\mathrm{N}$ Institute of Education (U.S.). Edu Division. 01978

Print Check holdings

Book 
The left-side facets on the Primo results page mimicked the order familiar to patrons from the previous WCL interface. When checked, the Expand My Results box returns PCI citations without full-text availability and linking to ILL. The tool bars at the top included some Primo installation links such as Ejournals A-Z, Help, EShelf, Account, and Sign-In. We added others to link back to spots on the main Library Web page, including: New Search, Databases, Class Guides (LibGuides), and Chat.

During testing, participants answered ten written questions designed to analyze certain tasks and approaches to typical searches, voicing their decisions into a recorder while navigating Primo. We avoided interacting with students during this process, simply reminding them when needed that the system was being tested, not their research skills. This tactic served both to elicit genuine responses as well as to alleviate the stress related to test taking generally.

After testing, we debriefed students about the experience, offering them an opportunity to provide suggestions for improvement of the system. To assure that participants also learned from the experience, after testing and debriefing concluded, we offered helpful search tips and gently corrected more critical misunderstandings, which students appreciated.

\section{Results}

We reviewed session notes and recordings for each participant, highlighting problems as well as unexpected strategies. Appendix A presents the questions we asked students. Table 2 shows the tasks intended, and a summary of results for each. While test takers technically answered most of the questions, they did not necessarily complete tasks in the expected manner. Although the artificial lab conditions of the study could not uncover authentic in situ searching strategies, the test questions did provide a useful structure for observing how participants 
navigated the discovery system, and the Thinking Aloud protocol combined with post-search debriefing offered context for participant thought processes and motivations. Some observed patterns follow.

Table 2 -Tasks and Results

\begin{tabular}{|c|c|}
\hline Tasks (by Question numbers) & Results \\
\hline $\begin{array}{l}\text { 1. Find a known book. Find if a } \\
\text { book is available here now. }\end{array}$ & $\begin{array}{l}3 \text { started in Everything scope; } 4 \text { limited to Linfield Library } \\
\text { scope (one signed in first). All found book in results, } \\
\text { although some had trouble locating the call number. }\end{array}$ \\
\hline $\begin{array}{l}\text { 2. Find a book via Summit that } \\
\text { is not in our library }\end{array}$ & $\begin{array}{l}5 \text { kept scope at Linfield Library initially ( } 3 \text { then changed to } \\
\text { Everything, but } 2 \text { failed to find books), } 2 \text { changed to } \\
\text { Everything; } 2 \text { changed to Advanced Search but one moved to } \\
\text { homepage and redid search under Everything. }\end{array}$ \\
\hline $\begin{array}{l}\text { 3. Notice facets to limit to a } \\
\text { specific format }\end{array}$ & $\begin{array}{l}\text { Most students did find the newspaper facet. } 4 \text { used } \\
\text { Everything, } 2 \text { Articles, one Advanced Search, } 2 \text { Exited Primo } \\
\text { to Homepage/ Research Databases. Several had trouble } \\
\text { choosing full text links because they did not understand the } \\
\text { vendor linking. }\end{array}$ \\
\hline $\begin{array}{l}\text { 4. Judging relevant books and } \\
\text { articles/ use facets/- Limit by } \\
\text { Available in Library (AIL). }\end{array}$ & $\begin{array}{l}\text { Most used Florida railroad history keywords and chose } \\
\text { results (articles or books) with those words. } 2 \text { limited to } \\
\text { article or print book by facets. Only one linked to AIL. One } \\
\text { used Linfield scope. }\end{array}$ \\
\hline $\begin{array}{l}\text { 5. Limit results to peer- } \\
\text { reviewed (PR) articles }\end{array}$ & $\begin{array}{l}7 \text { used Everything search, one Adv Search/Article; } 5 \text { found } \\
\text { PR facet, } 2 \text { used article facet and chose titles with PR in } \\
\text { results entries. One guessed "academic" by journal name. } \\
\text { One went to databases on homepage, found Ebsco ASP, } \\
\text { chose article with "academic journal" icon. }\end{array}$ \\
\hline $\begin{array}{l}\text { 6. Limit Format to DVDs in } \\
\text { facets. Limit to Available in } \\
\text { Library (AIL) }\end{array}$ & $\begin{array}{l}\text { Success for everyone, though via different paths. } 3 \text { limited to } \\
\text { Linfield scope, DVD in facet. } 2 \text { used Advanced search } \\
\text { limited to Linfield Library scope, } 4 \text { started in Everything, } \\
\text { limited to DVD via "more" \& "included" DVD (except. one } \\
\text { "excluded" all non-DVD). Then one further limited via AIL. }\end{array}$ \\
\hline 7. Find My Account link & $\begin{array}{l}\text { Easy for all. } 7 \text { chose My Account, } 2 \text { chose Eshelf from } \\
\text { toolbar }\end{array}$ \\
\hline $\begin{array}{l}\text { 8. Find online Journal title via } \\
\text { Primo, via Ejournals A-Z or } \\
\text { keyword search in Primo } \\
\text { Find our print holdings (via } \\
\text { advanced or default Primo). }\end{array}$ & $\begin{array}{l}\text { Task One: } 4 \text { used Everything; one Linfield; one- Advanced } \\
\text { Search/Everything; } 3 \text { went to Library page }-2 \text { of those } \\
\text { searched chosen database via journal name, one chose A-Z } \\
\text { list; } 3 \text { failed to identify we had online for } 2014 \text { - - Task } 2: \text { all } \\
\text { but one failed to understand location or holdings notations. }\end{array}$ \\
\hline
\end{tabular}




\begin{tabular}{|l|l|}
\hline $\begin{array}{l}\text { 9. Use facet to limit by Date } \\
\text { and by Language and } \\
\text { Articles }\end{array}$ & $\begin{array}{l}7 \text { successful. } 5 \text { used Everything, } 3 \text { limited via facet date } \\
\text { slider \& French; one scanned results for date, did not see } \\
\text { French facet; 3 used Advanced search/date then facets } \\
\text { French/Articles. One used Linfield scope found books but } \\
\text { no articles scope. }\end{array}$ \\
\hline $\begin{array}{l}\text { 10. Find the Research } \\
\text { Databases link from search } \\
\text { toolbar. }\end{array}$ & $\begin{array}{l}\text { Only one used databases link from Primo toolbar. All } \\
\text { others went to Homepage/Databases link, but all } \\
\text { answered the question }\end{array}$ \\
\hline
\end{tabular}

Navigation anomalies:

In general, participants did their best to find the answers to the test questions. When they knew the direct path to the answer, they took it confidently. More often, however, they resorted to finding cues on the site or using previous search experiences to get there. Most worked quickly, trying many paths, and often missing potential cues the first time through, ultimately prolonging the task. Others did not read questions thoroughly enough or did not understand what we were asking. For example, Question 4 asked for "relevant" articles about Florida railroad history. Most students simply put in keywords, created a results list, and called that answer done. They did not think about relevance except to note the keywords appeared in results for books and articles. One person even noticed the Sorted By feature was set at Relevance at top of the results list and then proceeded to use Edit/Find in the browser toolbar to locate instances of railroad on the page. The student used this technique on a later question as well, indicating a search habit perhaps implemented in other systems. Others also seemed to use habits acquired elsewhere in approaching all searches, even when unsuitable or unnecessary. Another student put quotes around every keyword in a search. A couple of students always used the Advanced Search feature while a few others limited most searches to the Linfield Library only scope. When a question requested articles, several participants always sought out the Research Databases listed separately on the library main search page, rather than search for articles through Primo. When 
debriefed about this choice later, a couple of upper-division students explained they had been told by librarians Primo was not a good place to look for articles, so it was not their habit to use it for that. Search scopes and facets caused other problems discussed in more detail below.

\section{Language anomalies:}

Many challenges to students seemed to stem from misunderstanding or not recognizing wording cues linked to successful paths. While they may eventually have found a correct answer, the searching in some cases proved to be fairly inefficient. Some of the language challenges had to do with unfamiliar library jargon used on labels. Question 8 was especially taxing in this regard. Those searching the journal title in Primo found a print journal record that lists "holdings," which most test takers ignored. When asked about this at debriefing, one student said she thought holdings meant a hold requested at circulation. Another declared during testing: "I have no idea what that means." Still another suggested he would ask a "circ student what it meant" if he were searching on his own. Similarly, some students ignored opportunities to link to full-text articles because they did not understand the notations for vendor collections (e.g., Sage Premier 2012) and volume coverage. This question also exposed failings to recognize meanings of location labels. Only one student (who worked with serials) understood what the "McMinnville Periodicals" location meant.

\section{Discussion}

The researchers presented the results and patterns of the study to the other librarians at our institution. Together we decided which issues seemed especially disruptive to the students' ability to search effectively and could be improved easily. While some problems proved too 
complex to change immediately, the librarians agreed the perspectives shared and navigation choices observed proved useful for interacting more knowledgably with students in classes and in reference consultations going forward. Since the participants all worked at the library, this awareness could even improve student worker training.

Below are some of the highlights of that discussion:

1. Scopes: Many students did not understand how to use the Primo scope filters (dropdowns) effectively. Many of them would try the default Everything search, then limit to the Linfield Library search, and never change the scope filters for successive searching. As a result, these students unwittingly limited subsequent searches to Linfieldonly materials. The researchers decided the "Everything" terminology of the first scope might be too vague. Following the lead of other Alliance libraries, the systems librarian changed the labels on scopes to spell out contents. Thus, Everything became: Linfield+Summit+Articles. (Note: Test-takers never used the WorldCat and Ebsco Only scopes to complete tasks nor did the researchers design tasks for this study to test the use of these scopes.)

2. Availability Signals: Yellow dots usually represent physical materials one can request via Summit, the consortial resource sharing system. However, the label for these items read "Check Holdings," and the researchers noticed students bypassing these during the tasks and asked about it during debriefing. The ambiguity of the label caused students to avoid dealing with that option. After much research and troubleshooting, the systems librarian noticed that one yellow dot label in the Primo code tables accounted for most of 
the Summit request options. She changed that label from "Check Holdings" to Summit to help signal to patrons the availability of such items for request through the consortium.

3. Journal coverage dates: As noted earlier, in one task, when students encountered information showing issues of journals in print, most did not understand what the term "holdings" meant. In this case, the standard holdings information came from Alma, the resource management part of the system, and as such, it did not represent a simple label change for Primo. Since this information is input according to the accepted standards for holdings records, the librarians decided to table dealing with a possible label change here for the future. Fortunately, trends toward electronic rather than print journals mean patrons increasingly never see this notation.

4. Facets: Students did not really understand that facets on the left (for format, author, subject, peer-reviewed, available in the library) were not offered unless the results included items in that category. Since the order of facets had been based on the old WCL model, the librarians discussed moving some facets. We moved subject and date closer to the top to feature the value of using subject and date more in teaching.

5. Details tab - Most students did not understand the Details tab included information about an item but was not a good place to find local information such as call number or coverage availability for journals. The librarians decided to include this concept in teaching and online help for now and to consider further testing on what wording change might be more effective. 
6. Quotation marks: Several students demonstrated they did not understand how to use quotation marks in searches. One student used quotes around every word, which led to very strange and unintended results. After debriefing with this student, the researchers suggested using quotation marks more selectively, to facilitate finding particular titles, or to bind phrases, such as "public education," which searched apart might retrieve too many irrelevant items. They also noted this for future reference in teaching.

7. Article search - Some, mostly upper class, students went directly to standalone vendor databases, such as EBSCOHost, because they had been told in previous instruction sessions that Primo was a bad place to find articles. (Note: Only one student tried the Ebsco Only scope but quickly backed out of it, completing the requested task in another way.) In fact, in the past searching for articles with WorldCat Local had been limited, and early forays with Primo before all institutions had migrated completely proved so unreliable that most of our librarians continued to feature Primo for finding books only. So it was not completely surprising to find the juniors and seniors tended to stick to familiar methods learned earlier. But with full consortial migration and significant system improvements, librarians at our institution now agree that Primo can be a great place for all students to find articles and some of us have even begun to teach searching first in Primo, especially for initial research exploration. 
Figure 2 - Primo After Changes

Toolbar view including WorldCat

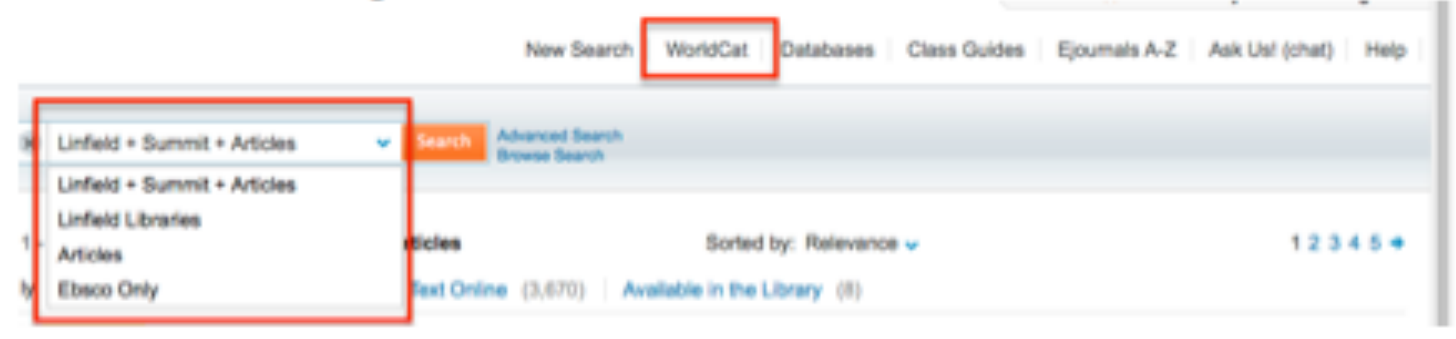

Results view: 4 scopes, new labels, all results show (no Expand Results box)

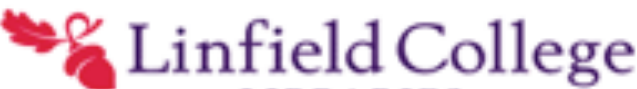

LIBRARIES

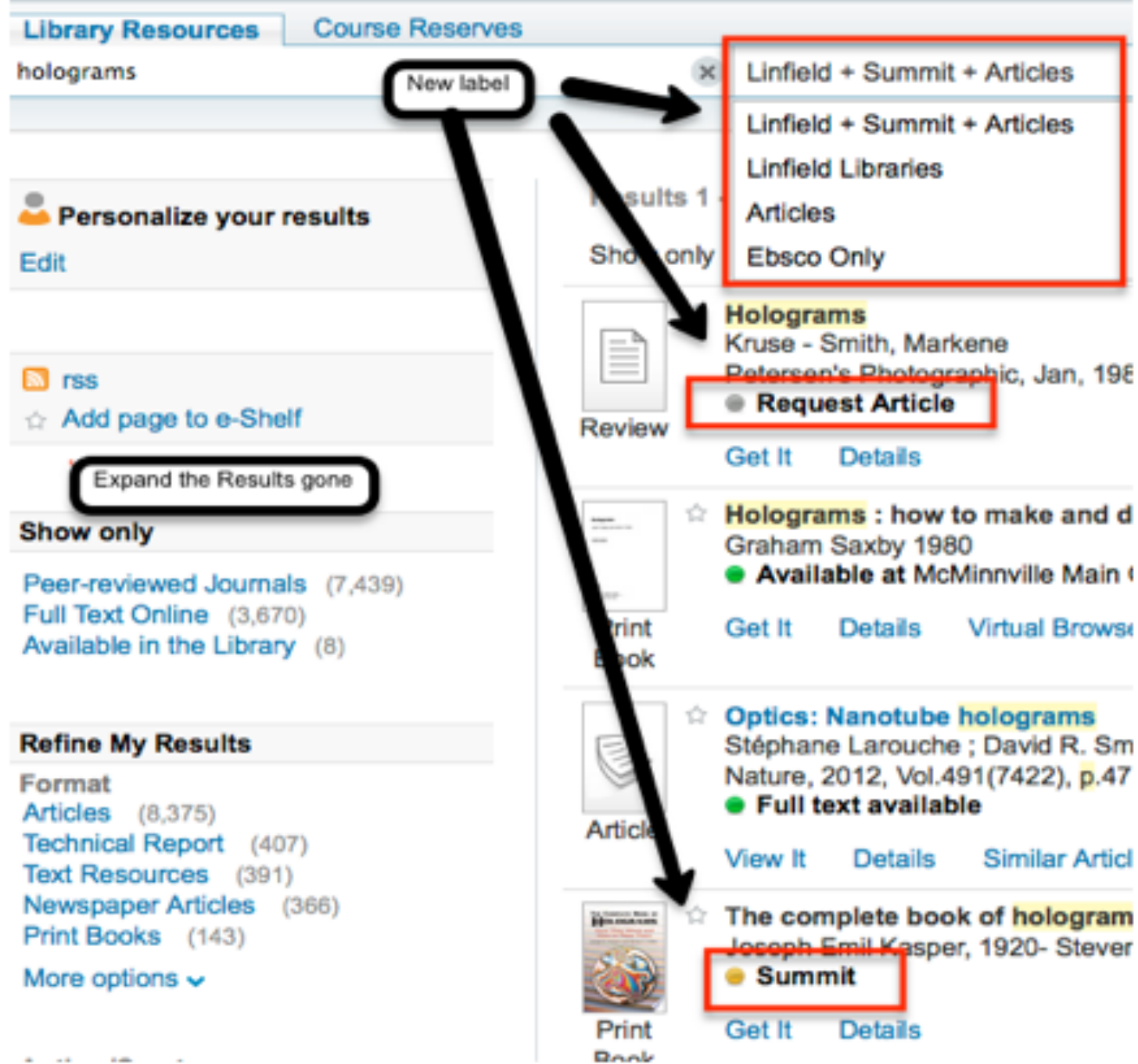




\section{Participant Suggestions:}

Debriefing with students after the testing helped the researchers to understand student searching strategies better and to identify teaching opportunities. The researchers also asked participants directly for suggestions to improve the system. Students complained most about clutter, which got in the way of intuitive navigation. They wanted less wording, simpler language, and a cleaner format. Many of the changes noted above to labels and scopes followed this advice. Librarians decided to table more complex alterations until after adopting the new Primo facelift promised in 2016, though they did decide to modify a few other functions in the spirit of simplifying the user interface.

1. WorldCat Discovery: While librarians would like the WorldCat scope to serve as a place to find materials outside Summit, or even combined with the default search, it does not work well for various reasons. Since it was also ignored by test-takers, librarians decided to remove it. Instead, we added a link to WorldCat Discovery in the header toolbar, until the time that a WorldCat API works effectively from within Primo. We usually need to mention this unintegrated WorldCat feature when relevant in teaching and during reference consultations. (Although also largely ignored, the Ebsco Only scope has been allowed to remain for testing purposes.)

2. Interlibrary Loan (ILL) for Articles: Before testing, Primo included only available (green dot) full-text article results because including non-full text items (grey dot) generally overwhelmed the search results. But if patrons wanted to see all PCI citations, including those requestable via ILL, they had to check a box entitled "Expand the Results" before searching. As found in the University of Minnesota study (Carter et. al 
2015), patrons rarely noticed or understood this feature, nor could librarians at Linfield easily convey this concept in classes. Fortunately, with positive developments in Primo over time, results including the grey dots now integrated more acceptably. In addition, due to streamlined local ILL practices, article requests from other libraries now often arrive within a day, or sometimes within hours. We thus decided to include all PCI selections, including non-full text items (grey dots) in the search results. Then in order to help students notice these items and to encourage them to request them via ILL, we changed the obscure and disappointing "No full text available" label to simply read "Request Article."

\section{Teaching after Web usability changes}

Librarians at Linfield teach a lot. While the college does not have a formal information literacy program, the librarians and course faculty do collaborate closely to integrate multiple library research sessions into the writing-intensive first year Inquiry Seminar (INQS) classes. This means that all students receive library instruction, mostly in the first semester. In addition, librarians and other faculty work together on numerous classes across the disciplines, covering sophomore through senior years. The librarians had been used to teaching Primo as just another portal, mostly for finding books. But with new developments in Primo, including language streamlining and other small changes implemented from the study, librarians at Linfield have paid more attention to learning advantages available in discovery systems and are focusing on teaching more conceptual aspects of research and information selection.

The systems librarian implemented agreed-upon changes in time for fall term 2015. Instruction librarians informally discussed the efficacy of the changes throughout the term and 
the impacts some of these changes had on teaching. The researchers had expected the modifications to simplify searching for patrons. What no one expected was how much clearing up a few basic wording ambiguities would facilitate both teaching and communication for librarians.

First, simplifying the availability labels resulted in boiling down the brief results to three easily understood expectations: "Available" (green - we have it), "Summit" (yellow - physical items - will take a few days), and "Request Article" (grey-ILL could take a few hours or days). The changes have also become a visual reminder of Summit and ILL, facilitating communication with new students and others about these services. After the change, one librarian declared he no longer had to think so hard, referencing Steve Krug's Don't Make Me Think (2006), but could now at a glance understand where to expect resources to be located. Obviously this enthusiasm could easily be passed on to students in the classroom or at the reference desk.

In addition, the new default label Linfield+Summit+Articles clarified what patrons could expect to find in the default scope. One librarian said this made it much easier to discuss with students the variety of resources available in any given search. Other lessons from teaching Primo followed from this observation.

\section{Focus on content}

Highlighting the content of multiple formats in Primo's results has become a useful discussion point in INQS classes, where first year students, usually just out of high school, struggle to discern the value or even the differences among resources available in the wider world. One librarian noted that students start to gain a solid foundation in being able to evaluate a source if they can immediately tell a book chapter, from an article, from a government report. 
Primo has become a natural way to get students to think about what they might encounter in research. Providing hands-on opportunities for them to identify and consider types of content in the context of a course's term project also opens up their expectations.

Spotlighting journal articles within results helps students recognize them and fosters conversations about when and why they can be useful in research. One of the questions students struggled most to answer in the Web usability study was how to access a specific journal title in Primo, either online or in print. Part of the reason that question proved difficult was that most students have only encountered articles as disembodied PDFs on a screen. They have a hard time realizing how articles relate to journals when the trappings of print publication still used to publish and arrange research articles have little meaning for them. Some of our teaching librarians try to mitigate this confusion in several ways. One librarian makes a point in class to have students connect articles as seen in physical print journals with those found through Primo. Another librarian gets students to cite an article for a class bibliography page in order to help them understand that citations still reflect the print-based world, despite the fact that most everyone retrieves electronic articles. In a related assignment, the librarian asks students to locate a research article by first limiting a search to peer-reviewed, looking in the results for longer articles by number of pages, and then finding a description in the details tab that suggests it's a study.

\section{Dealing with results}

Primo has also become a good method for orienting INQS students to "shop for topics," offering them experience browsing a large results set just to find a good research thesis. Carol Kuhlthau reiterates the importance of exploring a topic before committing to a research question 
and then beginning the resource gathering stage in earnest. Without this overview step, "students get mired in the collection stage of research and end up merely reporting on disconnected facts" (Maniotes and Kuhlthau 2014, 10). The Primo E-Shelf makes "explorational” browsing easy, by allowing students to mark resources as they go for later scrutiny. In this way, they can then build lists in the background while testing the waters with their ideas, browsing, narrowing, and broadening results along the way until a research focus emerges. Teachers can easily model this strategy and get students to try it with real topics in the classroom.

Primo also provides a good first step to teach students concepts common to searching any database or portal. Browsing facets without limiting first allows students to see how results fit into several disciplines and formats. Facets also provide a means for whittling down or broadening results by format, date, and other features. As one librarian put it, Primo "rewards" patrons for using facets. Another librarian noted that limiting the "collections" facet to results in Sociological Abstracts helped students recognize the "sociological" articles in a large retrieval. While many articles in this database require ILL requesting, the facet nevertheless exposes relevant content that might otherwise remain unfound. Discovering the existence of discipline specific databases in this way also offers a teaching moment and a segue into discussing them, where to find them, and when it might be better to use them. Additionally, all the concepts about using subject headings and facets can carry over to other databases without a lot of extra explanation.

\section{Algorithmic literacy}

Primo also provides the chance to educate students to be mindful of differences among databases both in content and search capabilities. Asher (2011) observed that students, 
overwhelmed with huge one-search discovery system results, were also largely unaware of how search engines influence those results. For instance, they tended to use familiar databases, such as JSTOR, unaware it may not include current content. Asher promotes the idea of "algorithmic literacy" noting that "[s]earch shouldn't be magic; it's only when its processes and algorithmic culture are demystified that our students become empowered to use it effectively" (11). Perhaps second-generation discovery systems like Primo have improved, offering better features to limit results. But all undergraduates need to be reminded to question not only what these and other portals contain, but in what ways, and maybe why, they boost and manipulate results.

One teaching librarian found that comparing a search in Google with one from Primo was a great way to discuss the content of retrievals and how they differ. What do the first pages in each case reveal? What ways does Google offer to modify results? How is Google Scholar different? Eli Pariser in the Filter Bubble (2011) revealed that the Google algorithm customizes results according to an end-user's search habits and interests, noting that “...there is no standard Google anymore" (2). Will different people using the same keywords retrieve the same results? These sorts of explorations in class offer great opportunities to enhance algorithmic literacy.

\section{Lessons Learned}

Students like things to be simple, familiar, and clearly understandable at a glance. And so do teachers. Creating plain, identifiable availability signals (Available, Summit, and Request Articles) allows everyone to find, discuss, and easily refer to these important delivery points. The simplified terminology works for the majority of cases, far outweighing the anomalies that crop up. Librarians tend to want to cover each eventuality, but the research in this study suggests that 
students ignore what they do not understand, which includes too many choices or conflicting messages.

Even student library workers can expose anomalies in a system. The common assumption that students who work in the library would be better at fulfilling the tasks in the test than other students did not seem to hold true with this study. Most of them did not act like experts using Primo and provided great insights for the researchers. Also, even though some of the participants were acquainted with the researchers, this fact did not seem to adversely affect the testing environment or results. While non-library worker students may provide more or different insights, this study did not suffer from a lack of data because the participants worked in the library. In fact, the data only bolster Nielsen's (2009) argument that usability testing offers reasonable results even under less than ideal conditions, and is certainly better than no testing. When modifications resulting from the usability testing cleared a few roadblocks with wording and navigation, they also created an opportunity for us to reflect on what teaching in the discovery environment might offer. Before this study, the librarians at our institution primarily used Primo as they had used WorldCat Local - to find books (local items) and then to switch to discrete research databases for articles. They had been frustrated with aspects of using Primo and were unable to identify how to start teaching with it more widely. But the changes, in tandem with information literacy conversations and theories in the ACRL Framework, inspired the librarians to try teaching discovery more conceptually. Viewing different formats and information together can give students an initial sense of how their topic fits into the world of scholarly writing. Then they can narrow the results in varied ways, including by discipline or even broaden further to include multidisciplinary dimensions. Similarly, Linfield librarians can help students, already familiar with searching large result sets like Google, to appreciate the 
value of facets and other features that facilitate locating academic content they need for college assignments. These concepts then transfer easily to introducing disciplinary databases, allowing librarians to spend less time showing students how to pull the levers and more time thinking about what content they see and how that compares with content discovered through Google and other familiar means of Internet searching.

Teaching librarians can profit by conducting simple Web usability studies themselves. During testing, they gain valuable personal insights about local user behavior that can subtly facilitate the way they teach, much more than will ever be gained by reading a selective summary of the study. One researcher noted that her limited view on the value of searching Primo for articles changed after observing students in action and talking with them afterward. The experience also has prompted ideas on what teaching possibilities in the discovery environment might offer. While not all teacher librarians can be part of these studies, it makes sense to involve public services librarians more in their design and discussion.

Similarly, there are certain advantages to being a teacher who also manages the Primo interface. The "teacher" shares the user experiences every day and so can observe functionality and ask students informally what they think. The Primo "manager side" then absorbs this intelligence, using it to troubleshoot, fix small problems, test solutions, and discuss priorities with other librarians. The demands of this dual role limit the multitasking librarian to minor customizations not requiring deep systems knowledge. On the other hand, sticking largely to the simple out-of-the-box Primo configurations also means the system may operate closer to vendor expectations, facilitating troubleshooting and evolving development.

Each library in the consortium configures Primo in slightly different ways based on local priorities, how other services like ILL are integrated, and even local language preferences. While 
the consortium shares data and a lot of functionality and expertise, Primo, the discovery interface, remains quite varied across institutions. Colleges still need to test their own patrons and work out interface access solutions locally.

\section{Next Steps}

We want to look for other ways to exploit the advantages of discovery searching in teaching. Can it be a challenge to Google, not only for undergraduates, but for graduate students and faculty as well?

We would like to follow-up with more user experience testing, not just to assess more formally how current changes have worked, but also to see where other roadblocks occur. Several problems students encountered in the study related to understanding how certain discovery mechanisms functioned. Language modifications helped in some cases, but librarians could not agree on wording fixes for others. Rather than guess at solutions, the researchers would like to focus testing on new areas and see if better answers emerge from the students themselves. In addition, we would like to test a greater variety of users to uncover other opportunities for improvement. While library student workers as participants provided invaluable and surprising results, we would like to test students who do not work in the library and perhaps also faculty.

\section{Conclusion}

Students need simple and familiar ways to approach the complex task of sorting through the mountain of results Primo and other discovery systems provide. If they do not understand what they have retrieved, they cannot interact with results effectively. Undergraduates do not have the same grasp of the research universe that their professors do, and therefore cannot filter 
results knowledgeably. Even professors and graduate students, who have these filters for their fields, need enough variety of results to find new content. Web-scale discovery systems like Primo are beginning to provide the critical mass needed to compete effectively with Google for academic research. And increasingly, these systems can provide more immediate access to subscribed and owned institutional content than Google. In addition, these discovery systems can provide these results without the "algorithmic bias" built into Google (Pariser 2011).

Obviously the limits of this study preclude specific results from achieving wide application across all libraries. Nevertheless, understanding how patrons actually navigate and use the library discovery systems can be key in any environment both to improving local systems effectively and to gaining the awareness of student perspectives and strategies to enhance teaching, reference services, and even staff training. Web usability testing offers a simple, yet orderly way to learn some of these elusive lessons. In this study, researchers implemented Web usability testing to improve Primo discovery for the local population, even in a shared consortial environment. In the process, changes implemented from the study not only helped librarians to teach Primo better, but also facilitated learning how to enhance teaching by using Primo. 


\section{References}

ACRL. 2015. "Framework for Information Literacy for Higher Education.” February 2. http://www.ala.org/acrl/standards/ilframework

Asher, Andrew. 2011. "Search Magic: Discovering How Undergraduates Find Information." Paper presented at the Annual Meeting of the American Anthropological Association, Montreal, Canada 2011. http://www.erialproject.org/wpcontent/uploads/2011/11/Asher_AAA2011_Search-magic.pdf

Breeding, Marshall. 2014a. "Library Systems Report.” American Libraries. April 15. http://americanlibrariesmagazine.org/2014/04/15/library-systems-report-2014/

Breeding, Marshall. 2014b. "Web-Scale Discovery Services Finding the Right Balance." American Libraries 45(1-2): 25.

Buck, Stefanie and Margaret Melinger. 2011. "The Impact of Serial Solutions' Summon on Information Literacy Instruction: Librarian Perceptions." Internet Reference Services Quarterly 16(4): 159-82. doi:10.1080/10875301.2011.621864

Carter, Sunshine, Jeff Peterson, and Jan Fransen. 2015. "Stand Back and Watch: The Impact of Ongoing Usability Testing.” In: ELUNA 2015, May 5 - 8, 2015, Minneapolis, MN http://documents.el-una.org/1289/1/StandBackAndWatch-20150508-1000am.pdf

Chisman, Janet, Sharon Walbridge, and Karen Diller. 1999. "Usability Testing: A Case Study." College \& Research Libraries 60(6): 552-69. doi:10.5860/crl.60.6.552

Comeaux, David J. 2012. "Usability Testing of a Web-Scale Discovery System at an Academic Library." College \& Research Libraries 19(2-4): 189-206. doi:10.1080/10691316.2012.695671

Deodato, Joseph. 2015. "Evaluating Web-Scale Discovery: A Step-by-Step Guide." Information Technology \& Libraries 34(2): 19-75. doi: 10.6017/ital..v34i2.5745.

Dominguez, Gricel, Sarah J. Hammill, and Ava Iuliano Brillat. 2015. "Toward a Usable Academic Library Web Site: A Case Study of Tried and Tested Usability Practices." Journal Of Web Librarianship 9(2-3): 99-120. doi:10.1080/19322909.2015.1076710.

ExLibris. 2016. "Primo Central Index: An Upgraded Research Experience." Ex Libris Primo Accessed April 25. http://www.exlibrisgroup.com/category/PrimoCentral

Gross, Julia and Lutie Sheridan. 2011. "Web Scale Discovery: The User Experience." New Library World 112 (5/6): 236-247. doi: 10.1108/03074801111136275

Hanrath, Scott and Miloche Kottman. 2015. "Use and Usability of a 
Discovery Tool in an Academic Library." Journal of Web Librarianship, 9(1):1-21. doi:10.1080/19322909.2014.983259.

Krug, Steve. 2006. Don't Make Me Think: Common Sense Approach to Web Usability. Berkeley, CA: New Riders.

Maniotes, Leslie K. and Carol C. Kuhlthau. 2014. "Making the Shift: From Traditional Research Assignments to Guiding Inquiry Learning." Knowledge Quest 43(2):8-17. http://files.eric.ed.gov/fulltext/EJ1045936.pdf.

McGillis, Louise and Elaine G. Toms. 2001. "Usability of the Academic Library Web Site: Implications for Design." College \& Research Libraries 62(4): 355-67. doi:10.5860/crl.62.4.355

Nichols, Aaron, Amber Billey, Peter Spitzform, Alice Stokes, and Catherine Tran. 2014. "Kicking the Tires: A Usability Study of the Primo Discovery Tool." Journal Of Web Librarianship 8(2): 172-195. doi:10.1080.19322909.2014.903133.

Nielsen, Jakob. 2000a. Designing Web Usability. Indianapolis, Ind.: New Riders. . 2000b. "Why You Only Need to Test with 5 Users." Nielsen Norman Group. March 19. https://www.nngroup.com/articles/why-you-only-need-to-test-with-5-users/ .2001. "First Rule of Usability? Don't Listen to Users." Nielsen Norman Group. August 5. https://www.nngroup.com/articles/first-rule-of-usability-dont-listen-to-users/. , 2009. "Discount Usability: 20 Years.” Nielsen Norman Group. September 14. https://www.nngroup.com/articles/discount-usability-20-years/ . 2012. "Thinking Aloud: The \#1 Usability Tool.” Nielsen Norman Group. January 12. https://www.nngroup.com/articles/thinking-aloud-the-1-usability-tool/.

Orbis Cascade Alliance. 2015. "Shared ILS Migration Complete." January 22. Orbis Cascade Alliance https://www.orbiscascade.org/sils-migration-complete

Pariser, Eli. 2011. The Filter Bubble : What the Internet Is Hiding from You. New York: Penguin.

Perrin, Joy Marie, Melanie Clark, Esther De-Leon, and Lynne Edgar. 2014. "Usability Testing for Greater Impact: A Primo Case Study." Information Technology \& Libraries 33(4): 5766. doi:10.6017/ital.v33i4.5174.

Richardson, Hillary A.H. 2013. "Revelations From the Literature: How Web-Scale Discovery Has Already Changed Us." Computers In Libraries 33 (4): 12-17, http://www.infotoday.com/cilmag/may13/Richardson--How-Web-Scale-DiscoveryHas-Already-Changed-Us.shtml 
Rose-Wiles, Lisa M. and Melissa A. Hofmann. 2013. "Still Desperately Seeking Citations: Undergraduate Research in the Age of Web-Scale Discovery." Journal of Library Administration 53(2-3):147-166. doi:10.1080/01930826.2013.853493.

Rubin, Jeffrey. Handbook of Usability Testing: How to Plan, Design, and Conduct Effective Tests. 1994. New York: Wiley.

Seeber, Kevin Patrick. 2015. "Teaching 'Format as a Process' in an Era of Web-Scale Discovery." Reference Services Review 43(1): 19-30. Accessed January 18, 2016. doi: 10.1108/RSR-07-2014-0023.

Thompson, JoLinda. 2014. Implementing Web-scale Discovery Services: A Practical Guide for Librarians. Lanham: Rowman \& Littlefield.

Valentine, Barbara, and Sarah Nolan. 2002. "Putting Students in the Driver's Seat: Web Usability Testing on a Shoestring.” Public Services Quarterly 1(2): 43-66.

Vaughan, Jason. 2011. Web Scale Discovery Services A Library Technology Report. Chicago: ALA Editions. 


\section{Appendix A: Questions Tested}

Instructions (to participants): We are testing the Linfield Libraries Search system. Please answer these questions from Linfield Search as much as possible. Remember we are testing the system usability, NOT your library skills.

1. Does Linfield have the book Arabian Jazz? If so what is the call number? If not, how can you request it from another library?

2. Does Linfield have any books on wombats? If so, what is the call number of one book. If not, how can you request it from another library?

3. Find an article on women in politics from a newspaper.

4. Do we have anything on Florida railroad history?

- How many titles actually seem to be about this topic (are relevant)?

- How many are relevant books? Are any of these available at Linfield?

- How many of them are relevant articles? Write down one title here:

5. Find an article on Mexican American immigration from an academic (peer-reviewed) journal.

6. Does Linfield have any DVD's on the topic of Facebook? If so, what is the call number and title:

7. Do you have any books checked out? How would you find out?

8. Do we have online access to an issue of the journal American Sociological Review in 2014? If so, jot down one article title from that issue:

Do we have any of these issues in McMinnville Periodicals section? If so, which years?

9. What materials on Dracula before the 1980's are listed in Linfield Search? How many are available in French? How many of these are articles?

10. What Research Databases do we have for Psychology majors? Philosophy majors? 